animals in Africa as a natural resource in order to assist in filling the world's lardor. The more scientific investigational work which has been carried out in this field has been brought together by the Commonwealth Agricultural Bureaux in a recent publication, issued as Technical Communication No. 16, entitled The Meat Production Potential of Wild Animals in Africa-A Review of Biological Knowledge (By Lee M. Talbot, W. J. A. Payne, H. P. Ledger, Lorna D. Verdcourt and Martha H. Talbot. Pp. vii +42. Farnham Royal, Bucks.: Commonwealth Agricultural Bureaux, 1965. 13s.6d.). This directs attention to the possibilities of exploiting some of the game animals in under-developed countries. The review points out that the African continent contains the greatest diversity of indigenous large mammals to be found anywhere in the world. The wild ungulates considered range from the 10 -lb. dik-dik to the 5 -ton African elephant. The determination of the numbers of animals present in an area has represented a major problem. In general, the most accurate estimations were made from light aircraft, and the results agreed closely with those obtained by Royal Air Force photo-reconnaissance planes. Some animals were marked so that they could be recognized later and their movements and growth-rates followed. Agriculturists and meat technologists will be interested in the figures given under the heading "Carcass Composition". Killing-out percentages quoted include the following: East African zebu steers, 40 to more than 60 ; wildebeest, 50 ; topi and kongoni, 53; and impala and gazelle, both about 60 . In general, the amount of fat is consistently low, so that the carcass yield is relatively constant within a given species.

\section{Soil Catenas}

Since Milne used the word 'catena' as a mapping unit in East Africa, some thirty years ago, to describe a sequence of soils, oxtending from hill top to valley bottom, which is repeated, across the contours of the landscape, it has been interpreted in various ways in different countries. Such matters as parent material, erosion, intensity of leaching and mobility of sesquioxides have tended to complicate the original concept, which was intended to apply to one climatic zone, a medium-rainfall area of the tropics, and to differences in level. It is most useful, therefore, to have a documented statement on the subject by J. P. Watson in Soils and Fertilizers (28, No. 4, 307, 1965). The same number conteins a review by Dan $H$. Yaalon of a Russian book on Soil Geographical Zoning of the U.S.S.R., and a description by W. E. Calton of a soil-map of Africa (scale $1: 5,000,000$ ) with an explanatory monograph by J. L. d'Hoore. The former is a systematic inventory of the natural soil and climatic resources of the U.S.S.R.; the latter is a large inventory of the soils of Africa with seven sheets of soil maps.

\section{Soil Survey of Great Britain}

THE work completed and in progress during 1964 , under the auspices of the Soil Survey Research Board of the Agricultural Research Council, is described in its seventeenth report (Pp. $\mathrm{v}+46$. London: Agricultural Research Council. Obtainable from H.M.S.O. 1965. $6 s$. net). Publications include a memoir on "The Soils and Land Use of the District around Aylesbury and Hemel Hempstead", two bulletins on the soils of the Middle Teign Valley and of six counties in the West Midlands, and a soil map of 432 squaro miles (sheet 57) around Forfar. Two more memoirs on the Mendip District and on the country around Haddington and Eyemouth, and eleven sheets of soil maps, are in the press. Members of staff of the Soil Survey also contributed 21 papers to scientific journals and conferences. This report contains short accounts of the nature of the soils found in various parts of Britain, with emphasis on unusual features, and some classifications of soil series. There is also a summary of the laboratory investigations that have been carried out. The Soil Survey is frequently called on to make special surveys, and the assistance rendered to such authorities as the Forestry Commission, the Nature Conservaney, the Agricultural Advisory Sorvices, and planning and archaeological departments is briefly recorded. There are also two maps showing the areas in which field work has been completed or is in progress.

\section{Pituitary Transplants in the Teleost}

J. N. BALL and his colleagues havo taken very offective advantage of the development of a technique for hypophysectomizing the viviparous teleost Poecilia (Mollienesia) formosa, and for establishing homografts of the pituitary (Phil. Trans. Roy. Soc., B: Functional Capacity of Ectopic Pituitary Transplants in the Teleost Poecilia formosa, Comparative Discussion on the Transplanted Pituitary. By J. N. Ball, Madeleine Olivereau, Anna M. Slicher, and K. D. Kallman. Pp. 69-99+platos 18-21. London: The Royal Society, 1965. 18s.; 2.70 dollars). The ectopic gland survives, but without the direct link with the hypothalamus on which its relationships with the central nervous system normally depend. It has thus become possible to analyse with some precision the degree to which the various adonohypophysial functions are influenced by signals from the contral nervous system. In some respects the results are similar to those that have been reported from studios of the ectopic pituitary in mammals. Abundant prolactin is secreted by the ectopic graft, but there is a marked reduction or elimination of the secre. tion of growth hormone and gonadotrophins. But the teleosts havo pursuod their own independent line of evolution, and it is not surprising, therefore, to find some interesting points of difference in their hypothalamoadenohypophysial relationships. Corticotrophin secretion seems to be less dependent on hypothalamic stimulation than it is in mammals, and in this respect there is some resemblance botween Poecilia and amphibians. More unexpected is the finding that the ectopic adenohypophysis of the fish secretes thyrotrophic hormone at a higher rate than normal. This means that in the intact animal the hypothalamus must bo exerting an inhibitory influence on this function, whereas in mammals, as is well known, the influence is oxcitatory. The situation in amphibians in this respect is somewhat obscure, although there is certainly some evidence for an excitatory influence. The authors conclude that at present Poecilia seems to be peculiar in the way in which its thyrotrophin secretion is regulated.

\section{New Zealand Geochemical Group}

Aт the University of Otago on August 18, 1965, during the annual conference of the New Zealand Institute of Chemistry, a meeting attended by twenty-one interested persons unanimously approved a motion by Prof. D. S. Coombs, seconded by Mr. A. H. Horn, to form a New Zealand Geochomical Group. Officers elected were Dr. J. Rogers, chairman, Mr. S. H. Wilson, secretary, and Dr. A. Ewart, with power to co-opt. This motion crystallized a recommendation from a meeting chaired by Dr. A. J. Ellis at Lower Hutt during the centenary of the New Zealand Geological Survey. The New Zealand Geochemical Group plans to promote discussion and co-operation in geochemical problems between scientists of different disciplines and backgrounds by a newsletter and symposia at conferences. Liaison is also proposed with geochemical societies overseas. It is hoped to arrange a meeting of the Group during the international symposium on "Volcanology" in New Zealand between November 21 and December 3, which a considerable number of geochemists from overseas will be attending. Anyone interested in the Group is invited to register with Mr. S. H. Wilson, Institute of Nuclear Sciences, Private Bag, Lower Hutt. 